\title{
Biogenesis, Function, and Applications of Virus-Derived Small RNAs in Plants
}

\author{
Chao Zhang ${ }^{1}$, Zujian $W_{u^{1}}$, Yi Li ${ }^{2}$ and Jianguo $W u^{1,2 *}$ \\ ${ }^{1}$ Key Laboratory of Plant Virology of Fujian Province, Institute of Plant Virology, Fujian Agriculture and Forestry University, \\ Fuzhou, China, ${ }^{2}$ Peking-Yale Joint Center for Plant Molecular Genetics and Agrobiotechnology, The National Laboratory of \\ Protein Engineering and Plant Genetic Engineering, College of Life Sciences, Peking University, Beijing, China
}

RNA silencing, an evolutionarily conserved and sequence-specific gene-inactivation system, has a pivotal role in antiviral defense in most eukaryotic organisms. In plants, a class of exogenous small RNAs (sRNAs) originating from the infecting virus called virus-derived small interfering RNAs (vsiRNAs) are predominantly responsible for RNA silencing-mediated antiviral immunity. Nowadays, the process of vsiRNA formation and the role of vsiRNAs in plant viral defense have been revealed through deep sequencing of sRNAs and diverse genetic analysis. The biogenesis of vsiRNAs is analogous to that of endogenous sRNAs, which require diverse essential components including dicerlike (DCL), argonaute (AGO), and RNA-dependent RNA polymerase (RDR) proteins. vsiRNAs trigger antiviral defense through post-transcriptional gene silencing (PTGS) or transcriptional gene silencing (TGS) of viral RNA, and they hijack the host RNA silencing system to target complementary host transcripts. Additionally, several applications that take advantage of the current knowledge of vsiRNAs research are being used, such as breeding antiviral plants through genetic engineering technology, reconstructing of viral genomes, and surveying viral ecology and populations. Here, we will provide an overview of vsiRNA pathways, with a primary focus on the advances in vsiRNA biogenesis and function, and discuss their potential applications as well as the future challenges in vsiRNAs research.

Keywords: RNA silencing, small RNAs, virus-derived small RNAs, DCLs, RDRs, AGOs, plant antiviral defense

\section{INTRODUCTION}

In plants and other eukaryotic organisms, small RNAs (sRNAs) have emerged as key players of RNA silencing in the regulation of various biological processes, including plant growth and development, host immunity and pathogen virulence. To date, a series of pathways beginning with different precursors and resulting in sRNAs of various sizes with dedicated functions has been elucidated in the model plant Arabidopsis through both forward and reverse genetic screens.

Small RNAs are grouped into two major classes: microRNAs (miRNAs) and small interfering RNAs (siRNAs). MiRNAs are generated from a primary transcript (pri-miRNA) containing a stemloop structure and processed into 20-25 nucleotide (nt) sRNAs by RNase III endonuclease DICERLIKE 1 (DCL1), with the exception of the DCL4-dependent miRNAs such as miR822, miR839, and miR859 (Rajagopalan et al., 2006; Ben Amor et al., 2009). Many other cellular proteins are also required for miRNAs metabolism from processing to degradation, such as Methyltransferase 
HUA ENHANCER1 (HEN1), zinc finger protein SERRATE (SE), dsRNA-binding protein HYPONASTIC LEAVES 1 (HYL1), G-patch domain-containing protein TOUGH (TGH), HEN1 SUPPRESSOR1 (HESO1) and a family of SMALL-RNA DEGRADING NUCLEASES (SDNs) reviewed in Xie et al. (2015). siRNAs are divided into four subgroups: trans-acting siRNAs (ta-siRNAs), heterochromatic-associated siRNAs (hc-siRNAs), natural antisense transcript siRNAs (nat-siRNAs), and virusactivated siRNAs (vasiRNAs), which are primarily generated from diverse perfectly double-stranded RNA precursors and excised by DCL1 and its homologs (DCL2, DCL3, and DCL4) either cooperatively or redundantly (Bouche et al., 2006; Axtell, 2013; Cao et al., 2014). sRNAs are recruited by an ARGONAUTE (AGO) ribonucleoprotein complex, referred to as the RNAinduced silencing complex (RISC; Poulsen et al., 2013; Carbonell and Carrington, 2015). The programmed sRNA/RISC targets and silences RNA or DNA through post-transcriptional gene silencing (PTGS) or transcriptional gene silencing (TGS), respectively, in a sequence-specific manner (Martinez de Alba et al., 2013). Several updated reviews regarding the functions of miRNAs and siRNAs in controlling a plenty of biological processes are available (Harfouche et al., 2015; Weiberg and Jin, 2015; Zhang, 2015).

In regard to virus-derived small RNAs (vsiRNAs), many studies have shown in various organisms that the production of vsiRNAs is linked to antiviral immunity via silencing the viral genomic RNA. Two lines of evidences, including the biogenesis of vsiRNAs and the viral suppressors of RNA silencing (VSRs)regulated counter-defense help us to understand the vsiRNAsmediated antiviral RNA silencing pathway. In this review, we mainly summarize the current knowledge of the biogenesis and function of vsiRNAs in plants and discuss their potential applications as well as their future challenges in crop breeding systems.

\section{BIOGENESIS OF VIRUS-DERIVED SMALL RNAS IN PLANTS}

Virus-derived siRNAs, a class of exogenous sRNAs, are one of the earliest discovered sRNAs (Hamilton and Baulcombe, 1999). The biogenesis of vsiRNAs, however, has not been clearly elucidated over the past decade. What is known has been deduced based on the insights from genetic analysis in Arabidopsis and vsiRNAs profiling from various plant species. It indicates that the biogenesis of vsiRNAs is analogous to that of endogenous sRNAs, which requires the actions of various DCLs, RDRs, and AGOs. Table 1 lists the specific plant DCLs, RDRs, and AGOs known to contribute to the biogenesis of vsiRNAs.

\section{Origin of Viral siRNAs}

Early models of the origin of vsiRNAs hypothesized that the double-stranded replication intermediates (RIs) of positivestrand RNA viruses trigger the activation of the production of vsiRNAs (Ahlquist, 2002). If this was the case, the read counts of vsiRNAs derived from both the positive and negative strand in the virus-infected host plant cells should be similar. However, profiling of vsiRNAs derived from Cymbidium ringspot virus (CymRSV)-infected plants led to several interesting observations: (i) vsiRNAs derived from the genomic or positive strand far outnumbered those derived from the negative strand; (ii) most vsiRNAs were concentrated in a limited number of hotspots in the CymRSV genome; and (iii) double-stranded vsiRNAs bound to VSR protein p19 appeared to contain mismatches, as they were more sensitive to RNase A digestion than fully double-stranded controls (Ahlquist, 2002). These observations and others suggest that vsiRNAs are derived from the processing of highly structured regions of genomic RNA rather than from the perfectly paired dsRNAs-like RIs (Molnar et al., 2005; Koukiekolo et al., 2009). Several recent vsiRNA profiling studies in diverse eukaryotes have revealed that there are hotspots for vsiRNAs generation and there is a clear preference for a polarity, which have similar vsiRNA distribution to CymRSV (Xu et al., 2012; Vives et al., 2013; Visser et al., 2014). These results show, at least for some viruses, that RIs do not contribute significantly to the biogenesis of vsiRNAs. Rather, dsRNA-like secondary structures of singlestranded (ss) viral RNAs are most likely the dominant source of vsiRNAs (Donaire et al., 2009; Szittya et al., 2010; Wang et al., 2010). There is limited research on the origin of vsiRNAs derived from DNA viruses. This was characterized in geminiviruses, a family of plant DNA viruses with one or two circular ssDNA genomes that are replicated via dsDNA intermediates by a rolling circle mechanism. The dsRNA-like structures of DNA viruses are dominantly formed by the annealing of converging sense/antisense transcripts (Chellappan et al., 2004; Aregger et al., 2012).

\section{Roles of DCLs in the Biogenesis of Viral siRNAs}

Members of the plant Dicer-like (DCL) protein family are the critical components of the RNA-silencing pathway that produce vsiRNAs of different lengths (DCL4: 21-nt, DCL2: 22-nt, DCL3: 24-nt; Deleris et al., 2006). In Arabidopsis, the production of siRNAs from plant RNA viruses is mainly catalyzed under hierarchical action of the enzyme activities of DCL4 and DCL2 (Deleris et al., 2006; Figure 1). These results were first verified with Tobacco rattle virus (TRV) infected $d c l$ combination mutants. Specifically, TRV-specific siRNAs accumulated as discrete 21- and 24-nt species in wildtype (WT) Arabidopsis, similar to that in $d c l 2$ mutants, while in $d c l 3$, and $d c l 2 / d c l 3$ double mutants, only 21 -nt siRNAs accumulated, suggesting that DCL4 is mainly responsible for the processing of 21-nt vsiRNAs from RNA viruses (Fusaro et al., 2006; Garcia-Ruiz et al., 2010). In the case when DCL4 is absent or its activity is reduced or inhibited by virus, DCL2 produces 22-nt vsiRNAs. Although the abundance is lower, they are sufficient to trigger protective immunity, thus rescuing antiviral silencing. In the $d c l 2 / d c l 4$ double mutant, DCL3 can produce 24 -nt vsiRNAs, which play a minor role in antiviral defense. Additionally, Bouche et al. (2006) reported the DCLs functions in the production of Cucumber mosaic virus (CMV)specific siRNA. Their results indicate that CMV siRNAs are produced by DCL4 in WT plants, or DCL2 and DCL3 in 
TABLE 1 | Plant DCLs, RDRs, and AGOs involve in the vsiRNA biogenesis and function.

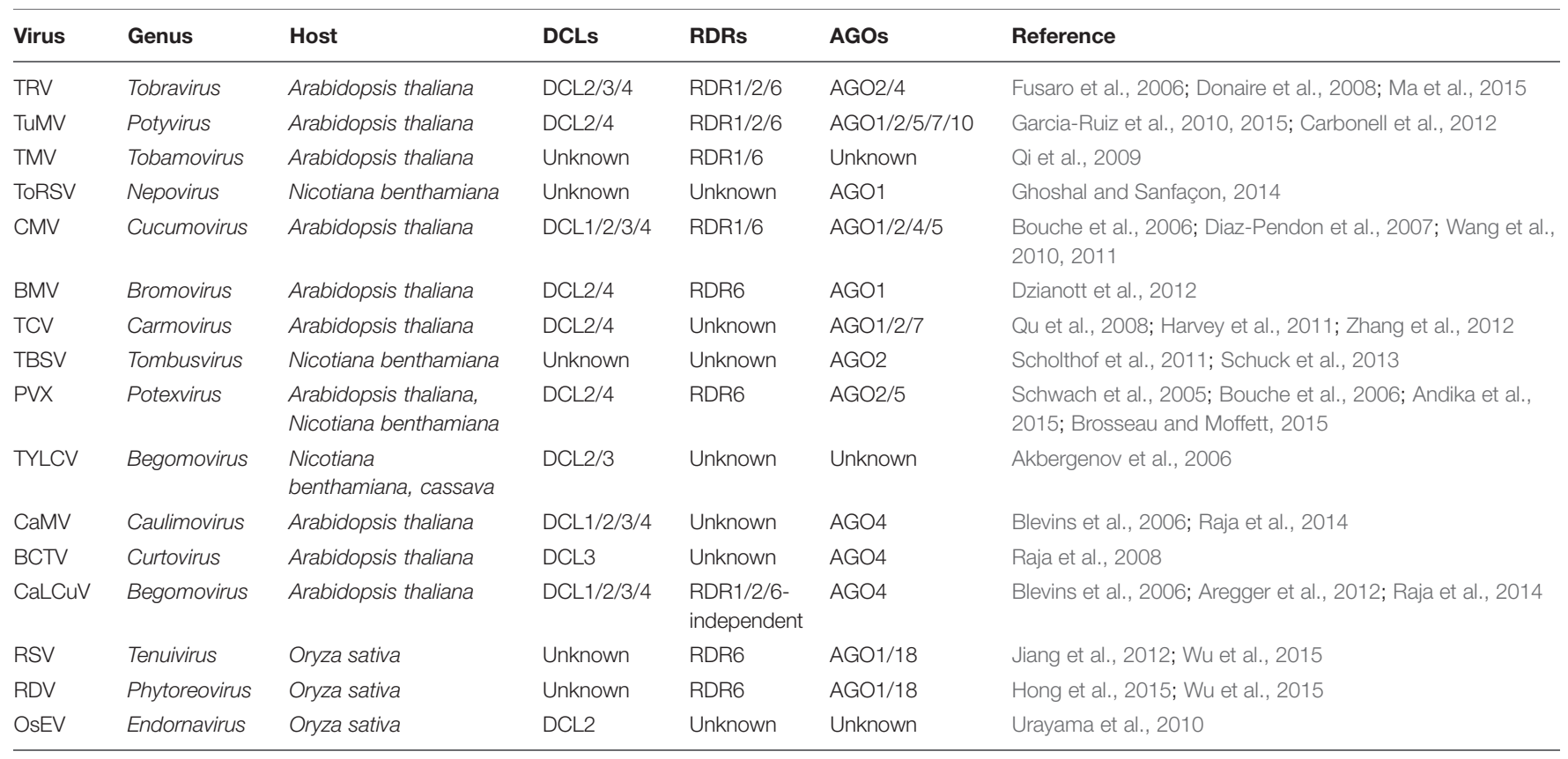

Specific plant DCLs, RDRs, and AGOs known to contribute to the biogenesis of vsiRNAs. TRV, Tobacco rattle virus; TuMV, Turnip mosaic virus; TMV, Tobacco mosaic virus; ToRSV, Tomato ring spot nepovirus; CMV, Cucumber mosaic virus; BMV, Brome mosaic virus; TCV, Turnip crinkle virus; PVX, Potato virus X; TYLCV, Tomato yellow leaf curl virus; CaMV, Cauliflower mosaic virus; BCTV, Beet curly top virus; CaLCuV, Cabbage leaf curl virus; RSV, Rice stripe virus; RDV, Rice dwarf virus; OsEV, Oryza sativa endornavirus.

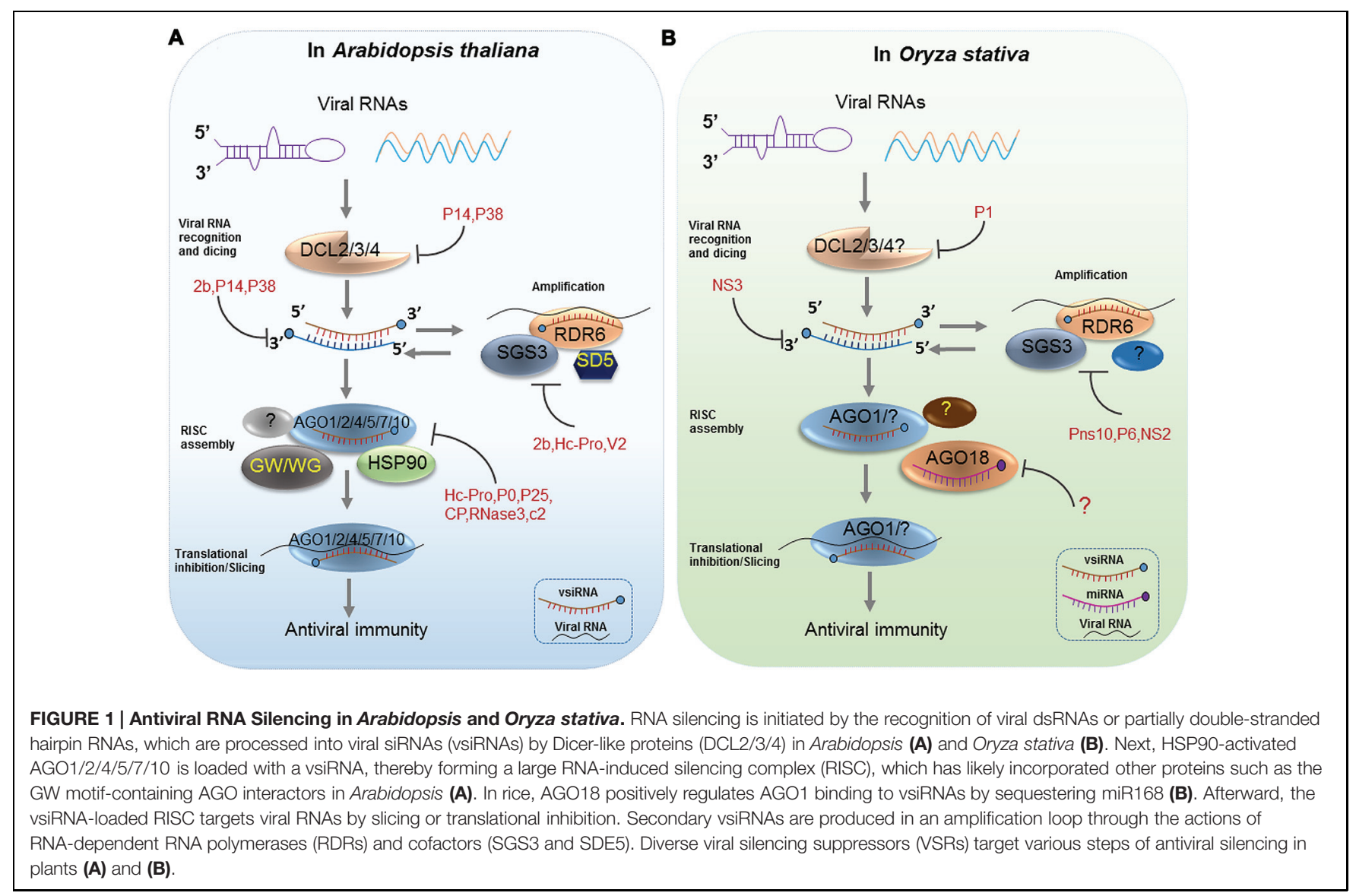


dcl4 mutants, which behave similar to ta-siRNAs. They also detected very low levels of 21-nt CMV-siRNAs in $d c l 2 / d c l 3 / d c l 4$ triple mutant plants, suggesting that DCL1 could produce 21nt CMV-siRNAs in the absence of DCL2, DCL3 and DCL4, although much less efficiently than ta-siRNAs (Bouche et al., 2006). Likewise, this group reported an opposite situation of DCLs activities in the production of Turnip crinkle virus (TCV)specific siRNAs in Arabidopsis. They found that DCL2 was the major contributor of TCV siRNAs, but DCL4 could also produce TCV siRNAs in the absence of DCL2 (Bouche et al., 2006). They later gave an interpretation for the discrepancy of DCL-dependent vsiRNAs processing between TCV and CMV. They thought DCL2 produced TCV siRNAs dominantly because DCL4 was inhibited by TCV but not because DCL2 had a stronger affinity than DCL4 for TCV dsRNA. In the Brome mosaic virus (BMV)-inoculated Arabidopsis Columbia-0 (Col0) plants, BMV RNA accumulated higher level than that in $d c l 2 / d c l 4$ double mutant plants but similar to that in $d c l 2$ or $d c l 4$ single mutant plants (Dzianott et al., 2012). As for the silencing suppressor (HC-Pro)-deficient Turnip mosaic virus (TuMV)infected Arabidopsis, blot assays showed that the 21-nt vsiRNA from the $5^{\prime}$ UTR region were sensitive to loss-of-function in DCL4, but in the absence of DCL4, this region yielded siRNAs that were 22-nt in length and dependent on DCL2 (Garcia-Ruiz et al., 2010). Recently, the differential requirement for DCL4 and DCL2 proteins in the inhibition of intracellular and systemic infection by Potato virus $X$ (PVX) in Arabidopsis was also reported (Andika et al., 2015). In rice, there are six putative DCL proteins (OsDCL1, OsDCL2a, OsDCL2b, OsDCL3a, OsDCL3b, and OsDCL4). Liu et al. (2007) found that OsDCL4 is the major Dicer responsible for the generation of 21-nt siRNAs that are associated with inverted repeat transgenes and ta-siRNAs derived from the endogenous TAS3 gene and OsDCL1, but not OsDCL4, is important for miRNA accumulation. However, of the six rice DCLs, their function in vsiRNA biogenesis remain poorly understood. Interestingly, rice DCL2 negatively affected maintenance of Oryza sativa endornavirus (OsEV), an endogenous dsRNA virus by increasing the accumulation of vsiRNAs, and indicated that rice DCL2 plays a major role in processing vsiRNA from OsEV (Urayama et al., 2010). Functions of rice DCLs in vsiRNAs biogenesis are always deduced from their homology to Arabidopsis DCLs. However, Xu et al. (2012) found that the distribution of vsiRNAs derived from Rice stripe virus (RSV), a negative-strand RNA virus, is very different in rice, Nicotiana benthamiana, and Laodelphax striatellus (insect vector). This suggests that the origins of vsiRNAs derived from different hosts are likely distinct.

Although the biogenesis of vsiRNAs by DCLs has been extensively documented in plant RNA viruses, little is known regarding viruses with DNA genomes. Indeed, the vsiRNAs biogenesis pathway of plant DNA viruses, which have a dsDNA intermediate stage, differs from that of RNA viruses (Chellappan et al., 2004; Akbergenov et al., 2006; Blevins et al., 2006). For instance, Geminiviruses trigger accumulation of various vsiRNA classes. Specifically, in begomovirus-infected $N$. benthamiana and cassava, three major size-classes of vsiRNAs, 21-, 22-, and 24-nt, are generated, and more than one DCL is involved in their biogenesis (Akbergenov et al., 2006). DCL3 is required to produce 24-nt siRNAs, while the production of the 22-nt siRNAs depends on DCL2, as well as other as yet unidentified DCL activities. From the studies of another geminivirus, Cabbage leaf curl virus (CaLCuV), DCL1 also processes some CaLCuV long dsRNAs into residual 21-nt vsiRNAs in the absence of DCL2, DCL3, and DCL4 (Blevins et al., 2006). In the case of plant viruses with a dsDNA genome, such as Cauliflower mosaic virus (CaMV), 21-, 22-, and 24-nt siRNAs from both sense and antisense polarities, coding and non-coding regions accumulated in CaMV-infected Arabidopsis (Blevins et al., 2006). DCL3 and DCL2 are required for the biogenesis of 24- and 22-nt CaMV siRNAs, respectively. Furthermore, the key role of DCL1 in the biogenesis 21-nt siRNAs from CaMV leader region was confirmed by the finding that high levels of 21-nt CaMV siRNAs accumulated in $d c l 2 / d c l 3 / d c l 4$. Taken together, unlike siRNA derived from RNA viruses, current knowledge suggests the accumulation of vsiRNAs from DNA viruses requires the action of all four DCL enzymes in a coordinated and hierarchical manner.

\section{Roles of RDRs and AGOs in the Biogenesis of Viral siRNAs}

Mechanistically, the biogenesis of viral siRNAs consists of two phases: DCL-dependent initiation phase and RDR-dependent amplification phase. RDRs play important roles in a second round of vsiRNA formation following viral RNA replication- or high-structural dsRNA-triggered biogenesis of primary siRNAs. The process of secondary siRNA-generation is thought to be similar to the RDR6-dependent tasi-RNA pathway. Specifically, primary vsiRNAs initiate the PTGS process involving diverse functional AGOs with RNase H-type activity (discussed latter) in plants. PTGS pathways recruit suppressor of gene silencing 3 (SGS3, a protein that blocks RNAs degradation), a putative RNA trafficking protein SDE5, and the RDR6 to transform cleaved ssRNA fragments into long, perfect dsRNA precursors. Then, these are subsequently processed into 21-nt siRNAs by DCL4 and its dsRNA binding partner DRB4 or 22-nt siRNAs by DCL2 (Dalmay et al., 2000; Mourrain et al., 2000; Gasciolli et al., 2005; Bouche et al., 2006; Martinez de Alba et al., 2015). Thus, it is assumed that an amplification loop is established whereby siRNA-guided AGO1 cleavage of viral transcripts leads to the RDR6/SGS3/SDE5-dependent production of dsRNAs, which serves as a substrate for the DCL-dependent formation of secondary vsiRNAs (Voinnet, 2008; Mallory and Vaucheret, 2009, 2010; Figure 1). In the beginning, there was some indirect evidence to support the role of host RDRs in vsiRNAs biogenesis and antiviral defense. First, host RDRs' activity is induced after virus infection. For instance, in tobacco mosaic virus (TMV)-infected tobacco leaves, a host polymerase RDR activity was stimulated by TMV (Romaine and Zaitlin, 1978). Moreover, loss-of-function mutations in host RDRs lead to hyper-susceptibility to virus infection (Dorssers et al., 1982; Xie et al., 2001; Schwach et al., 2005). Later, profiles of vsiRNAs in RDR mutants by deep sequencing directly revealed that host RDRs play a role in vsiRNAs biogenesis (Donaire et al., 2008; 
Wang et al., 2010). Among the six RDR genes that are encoded by the Arabidopsis genome, the functions of RDR1, RDR2, and RDR6 have been well demonstrated. The production of CMVderived siRNAs in the absence of the CMV VSR protein $2 b$ is largely dependent on RDR1 originally (Diaz-Pendon et al., 2007). Wang et al. (2010) found that there is a twofold decrease in the relative abundance of viral siRNAs in CMV-infected $r d r 1 / r d r 6$ double and $r d r 1 / r d r 2 / r d r 6$ triple mutants plants compared to $r d r 1$ and WT plants, suggesting RDR1 and RDR6 are all required for amplification of CMV-derived siRNAs. They also suggested that RDR1 preferentially amplifies the $5^{\prime}$-terminal end of the three genomic RNAs of CMV, whereas RDR6 amplifies the remaining regions (Wang et al., 2010, 2011). Consistent with these studies, another group found that both RDR1 and RDR6 play important roles in biogenesis of TMV-Cg siRNAs in virus-infected cells (Qi et al., 2009). The biogenesis of TRV- and TuMV-derived siRNAs involves the combined activity of RDR1, RDR2, and RDR6 (Donaire et al., 2008; Garcia-Ruiz et al., 2010). In rice, there are five RDR genes that have been annotated (Zong et al., 2009) but no insights to their roles in the biogenesis of vsiRNAs was provided to date except for the findings given by Jiang et al. (2012). They were the first to report that rice RDR6 plays a role in the accumulation of siRNAs derived from RSV genomic RNA. Through deep sequencing, they found that compared to the WT, the abundance of the RSV-derived siRNAs showed a 53\% reduction in OsRDR6 knockdown transgenic plants in which transcription levels were extremely reduced (Jiang et al., 2012). Recently, the same group confirmed the function of RDR6 in Rice dwarf virus (RDV) vsiRNA biogenesis. They found that the accumulation of RDV vsiRNAs was reduced in the OsRDR6 knockdown transgenic plants (Hong et al., 2015).

The biogenesis of RDR-dependent secondary vsiRNAs requires activity of AGOs, which serve as the effector proteins functioning in the antiviral RNA silencing. In Arabidopsis, there are 10 AGOs, categorized into three clades, while rice has 19 AGOs classified into four clades (Morel et al., 2002; Nonomura et al., 2007; Vaucheret, 2008). Many reports have shown that Arabidopsis AGO1, AGO2, AGO5, and AGO10 act in PTGS targeting RNA viruses (Qu et al., 2008; Harvey et al., 2011; Scholthof et al., 2011; Carbonell et al., 2012; Ghoshal and Sanfaçon, 2014; Brosseau and Moffett, 2015; Carbonell and Carrington, 2015; Garcia-Ruiz et al., 2015; Ma et al., 2015). For rice, little is known regarding how the various AGOs regulate antiviral RNA silencing except for AGO1 and AGO18, which synergistically play a role in antiviral defense (Figure 1; Du et al., 2011a; Wu et al., 2015). Actually, the role of AGOs in vsiRNAs biogenesis is almost restricted to their effector activity in the PTGS pathway. Specifically, AGOs associate with vsiRNAs to target complementary viral RNAs, and the cleaved ssRNAs are source of production of RDR-dependent secondary vsiRNAs.

\section{Suppression of Viral siRNAs Biogenesis by Various VSRs}

In the arms race between hosts and viruses, viruses developed potent VSRs that can target multiple steps of RNA silencing pathway to counter host antiviral strategies (Csorba et al., 2015; Wieczorek and Obrepalska-Steplowska, 2015). Apparently, the hallmark of the antiviral silencing response is the DCL-dependent production of vsiRNAs, thus the biogenesis of vsiRNAs is one important target of various VSRs. VSRs have ability to block the vsiRNA biogenesis by inhibiting DCL proteins and/or cofactors activity, sequestrating dsRNA/siRNA or AGO protein destabilization prior of RISC assembly. For instance, in the presence of TCV P38, siRNAs are undetectable, suggesting P38 acts to suppress DCL's activity (Qu et al., 2003). Deleris et al. (2006) later demonstrated using genetic analysis that P38 inhibits DCL4 but not DCL2. Moreover, P1 of RYMV also has ability to inhibit DCLs activities including both DCL4 and DCL3 (Lacombe et al., 2010; Weinheimer et al., 2010; Gillet et al., 2013). Some VSRs, such as Pothos latent aureusvirus (PolV) P14, TCV p38, CMV 2b, and RSV NS3 have been described to bind dsRNAs in a size-independent manner and therefore to block vsiRNA maturation (Merai et al., 2005; Deleris et al., 2006; Goto et al., 2007; Xiong et al., 2009). Furthermore, other VSRs such as RDV Pns10, CMV 2b, and Rice yellow stunt virus (RYSV) P6 block secondary siRNA biogenesis by downregulating RDR6 expression or suppressing the activity of RDR1, which are critical for secondary siRNAs synthesis (Diaz-Pendon et al., 2007; Ren et al., 2010; Guo et al., 2013). RSV NS2 as well as V2 protein of Tomato yellow leaf curl virus (TYLCV) directly interact with SGS3, the cofactor of RDR6, and compete with SGS3 for dsRNA binding (Glick et al., 2008; Fukunaga and Doudna, 2009; Kumakura et al., 2009; Du et al., 2011b; Figure 1). Potyvirus HC-Pro, one of the best characterized viral silencing suppressors, plays multiple roles in the suppression of vsiRNAs biogenesis, such as ds-siRNA binding, blocking HEN1 methyltransferase, HEN1 binding, blocking primary siRNA biogenesis by RAV2 interaction, RDR6 downregulation. A comprehensive review on the current knowledge of the diverse VSRs and their strategies to suppress vsiRNAs biogenes is available (Csorba et al., 2015).

Taken together, these findings support a model for vsiRNA biogenesis in plants in which DCL4 processes various viral dsRNA transcripts into primary vsiRNAs; RDRs and AGOs produce secondary vsiRNA through amplification. However, VSRs can inhibit the production of vsiRNAs by countering multiple steps of the antiviral silencing pathway. Notably, questions such as how, when, and where in the cell vsiRNAs are initially accessed by the RNA silencing machinery remain elusive.

\section{ROLES OF VIRUS-DERIVED SMALL RNAs IN ANTIVIRAL DEFENSE}

Besides the cellular components involved in vsiRNA biogenesis, there is accumulating evidence that the vsiRNA themselves are directly playing roles in antiviral immunity in plants. Considering the general function of sRNAs in directing RISC to target transcripts for PTGS or TGS, it is easy to assume that the main role of vsiRNAs is to target viral mRNA molecules. This may be a more effective method to inhibit viral replication than the production of primary vsiRNAs by DCL-dependent action 
on the RIs or highly structural dsRNA derived from the viral genome.

\section{VsiRNAs Function to Downregulate Viral RNAs}

Virus-derived small interfering RNAs are recruited by diverse AGOs to form RISC and direct the degradation of viral RNA molecules through PTGS in a sequence-specific manner (SimonMateo and Garcia, 2006). AsatsiR-12, an artificial siRNA derived from the satellite RNA (satRNA) of SD-CMV (a severe field Shan-Dong strain), which targets the $3^{\prime}$ UTR of CMV RNA and triggers the RDR6-dependent antiviral silencing pathway, has a positive effect on antiviral defense. The accumulation of CMV RNAs was reduced in the CMV- $\Delta 2 \mathrm{~b}$-infected transgenic plants expressing asatsiR-12 but this reduction was inhibited by the 2b suppressor ( $\mathrm{Zhu}$ et al., 2011). Their findings provided the first demonstration that viral satRNAs could mediate silencing against their helper virus. However, whether any AGO protein is involved in the silencing process as part of an active vsiRNARISC was not demonstrated at that time. Later, plenty of in vitro experiments involving different combinations of cellfree systems and viruses were conducted and results have shown the existence of endonucleolytic of antiviral RISCs but not directly AGOs (Szittya and Burgyan, 2013). The slicer activity of AGOs was verified by using in vitro assays involving cytoplasmic extracts of evacuolated tobacco protoplasts (Iki et al., 2010; Schuck et al., 2013). For instance, 'RISC formation/cleavage assay' and 'replication inhibition assay' showed that AGO1, AGO2, AGO3, AGO5, AGO7 and AGO10 had slicer activity with 21- and 22-nt siRNAs and thus inhibited RNA replication of TBSV in vitro (Schuck et al., 2013). Actually, in vivo experiments have indicated that $N$. benthamiana AGO with similarity to Arabidopsis AGO2 is involved in antiviral defense against TBSV (Scholthof et al., 2011; Odokonyero et al., 2015). A recent study on the antiviral role of $\mathrm{AGO} 2$ has shown that AGO2, AGO10, and to a lesser extent AGO1 associate with vsiRNAs derived from HC-Pro-deficient TuMV-AS9 (GarciaRuiz et al., 2015). Until now, Arabidopsis AGO1, AGO2, AGO5, AGO7, AGO10, and rice AGO1 and AGO18 are all the AGOs reported that associate with vsiRNAs upon virus infection, reviewed in Carbonell and Carrington (2015; Figure 1). Notably, previous studies on miRNA-mediated antiviral RNA silencing have revealed that many molecular chaperones, such as HSP90 and GW/WG motif-containing proteins, assist in or promote the antiviral defense response (Mayor et al., 2007; Iki et al., 2010, 2012; Earley and Poethig, 2011; Yang et al., 2012). Here, we hypothesized that the vsiRNA-mediated antiviral RNA silencing is likely to require various molecular chaperones (Figure 1). However, to date, no evidence verifies this. Additionally, there is still much that remains missing from our knowledge of vsiRNA-mediated antiviral defense due to several obstacles: (i) It remains unknown whether the majority of, if not all, vsiRNAs can load into specific AGO proteins; (ii) Even though some AGO proteins play a role in virus infection and are able to bind vsiRNAs, the RISC complex alone may not be able to access target the viral genome due to their complex secondary structures or VSR activity; (iii) At present, evidence that specific vsiRNAs can target the viral genome for inhibition of virus infection in vivo is limited. Therefore, the efficiency of antiviral RNA silencing may be determined by the accessibility of target sites (Simon-Mateo and Garcia, 2006). More research should be done on these aspects to make more advancement, which would give us more insight into vsiRNA-mediated antiviral defense through PTGS.

\section{VsiRNAs Function to Downregulate Viral DNAs}

Virus-derived small interfering RNAs can also be recruited by AGO proteins to form antiviral RISC that target viral DNA. It has been reported in plants that DNA methylation not only stabilizes transposons in the genome but is also involved in defense against invasive viral DNA genomes guided by abundant vsiRNAs (Chellappan et al., 2004; Vanitharani et al., 2005; Moissiard and Voinnet, 2006). DNA methylation at gene promoters can be triggered by dsRNAs through the RNA-directed DNA methylation (RdDM) pathway and induces TGS. The RdDM pathway requires 24-nt siRNAs for de novo DNA methylation of cytosines in all sequence contexts and AGO4 to target transcripts (Chan et al., 2004; Xie et al., 2004; Henderson et al., 2006). However, there is little molecular evidence of a vsiRNA-mediated RdDM pathway in plant antiviral defense. Studies on vsiRNA-mediated RdDM pathway have been conducted based on ssDNA plant geminivirus (Brough et al., 1992; Ermak et al., 1993; Wang et al., 2003, 2005; Raja et al., 2008). A group has shown that Arabidopsis plants defective in methyltrasferase or related cofactor activity are hypersensitive to geminivirus infection, suggesting that the viral genome is targeted by RdDM. They also demonstrated that Beet curly top virus L2-mutant DNA present in tissues that have recovered from infection is hypermethylated and that host recovery requires AGO4, a component of RdDM pathway (Raja et al., 2008). Recently, the same group reported that Arabidopsis Doublestranded RNA Binding 3 (DRB3) functions with DCL3 and AGO4 to induce repressive viral genome methylation against geminiviruses (Raja et al., 2014). This work demonstrates that the vsiRNA-mediated RdDM pathway is likely the predominant defense approach for hosts to counter plant DNA viruses during infection. Furthermore, we hypothesized that the vsiRNAmediated RdDM pathway also requires various host factors such as reiterated GW/WG repeats, a conserved effector motif on the plant-specific DNA-directed RNA polymerase IVb (PolIVb), also called the AGO hook. As previous studies described, they are binding platforms for AGO4 and are essential for the biogenesis of 24-nt siRNAs (Figure 1; El-Shami et al., 2007).

\section{VsiRNAs Function to Downregulate Host Transcripts}

Some have hypothesized that viruses might use sRNAs to silence specific host genes when there is near perfect complementarity (Addo-Quaye et al., 2008). However, the potential role of viral 
siRNAs in regulating host gene expression has rarely been reported. This idea can be first exemplified by the disease symptoms induced by the CMV Y-satellite RNA (Y-Sat), which relies entirely upon its helper virus (CMV) for replication and movement. In one instance, viral siRNA derived from the CMV-Y satellite RNA (Y-Sat) can specifically target the 22nt sequence in CHLI mRNA, encoding a magnesium chelatase subunit. Down-regulation CHLI leads to impairment in the chlorophyll biosynthesis pathway and the resulting yellowing symptom in the leaves (Shimura et al., 2011). In another case, two Peach latent mosaic viroid (PLMVd)-derived siRNAs specifically target host CHLOROPLASTIC HEAT-SHOCK PROTEIN 90 transcripts, resulting in the albino phenotype characteristic of peach leaves infected with PLMVd (Navarro et al., 2012). Recently, by performing artificial microRNA experiments in a transient expression system and by using RNA ligase-mediated rapid amplification of $\mathrm{cDNA}$ ends, a single small RNA derived from the virulence modulating region of two Potato spindle tuber viroid (PSTVd) variants was characterized. It targets several callose synthase genes of tomato plants (CalS11-like and CalS12like), which are essential for callose formation during pathogen infection (Adkar-Purushothama et al., 2015). Intriguingly, we also identified a sRNA derived from a rice virus with the potential to target rice endogenous transcripts and induce abnormal phenotypes in rice (unpublished). These observations indicate vsiRNAs possess an ability to silence specific host genes with nearly perfect complementary. Nonetheless, according to results from degradome sequencing datasets from virusinfected plants and/or 5' Rapid Amplification of cDNA Ends analysis of putative transcripts show that only rare endogenous genes were targeted by characterized siRNAs (Li et al., 2013; Miozzi et al., 2013), suggesting that vsiRNAs only occasionally regulate the host gene expression through PTGS.

\section{Suppression of vsiRNA Function by Various VSRs}

Current research has verified the functions of vsiRNAs in targeting viral RNAs or DNAs and, occasionally, host transcripts. In turn, many plant viruses evolved VSRs counteract the antiviral silencing process mostly through arresting the functional vsiRNAs-RISC assembly (Csorba et al., 2015). Coimmunoprecipitation and small RNA profiling revealed that Potyvirus HC-Pro can associate with vsiRNAs during TuMV infection, suggesting that HC-Pro may interfere with vsiRNAs function in antiviral defense by binding vsiRNAs and blocking vsiRNA-RISC assembly (Garcia-Ruiz et al., 2015). P25 can inhibit the antiviral RNA silencing pathway by precluding AGO proteins from accessing viral RNA, as well as by directly inhibiting the formation of RNA silencing machinery (Brosseau and Moffett, 2015). Polerovirus P0 interacts with E3-ligase S-phase kinase regulated protein 1 (SKP1) through its F-box motif to enhance the degradation of multiple AGOs (AGO1, 2, 4-6, 9) before holo-RISC assembly. ToRSV suppressor coat protein (CP) binds to AGO1 to suppress its translational inhibitory activity and to enhance AGO1 degradation through autophagy (Karran and Sanfacon, 2014). RNase 3, a VSR encoded by Sweet potato chlorotic stunt crinivirus (SPCSV), affects vsiRNA function by using a completely different strategy, in which RNase3 cleaves 21-24-nt vsiRNAs into 14 bp products and renders them inactive, thus effectively preventing the formation of antiviral RISC (Kreuze et al., 2005; Cuellar et al., 2009). C2 protein, encoded by DNA virus Beet severe curly top virus, is an effector that counteracts antiviral defense by interfering with gene silencing and metabolic defense responses. C2 mediates a decrease in DNA methylation, which is linked with reduced accumulation of siRNAs derived from the methylated promoters, to result in upregulation of the corresponding coding genes (Yang et al., 2013; Figure 1). Regrettably, the activity of VSRs encoded by rice viruses in suppression of vsiRNAs function is completely unknown.

Though many evidences indicate that vsiRNAs play a key role in plant antiviral RNA silencing, the molecular mechanisms are elusive. Much work on the studies of biological roles of specific vsiRNAs and function mechanism of VSRs should be done in the future to further extend our understanding on the vsiRNAs function.

\section{THE APPLICATION OF VIRUS-DERIVED SMALL RNAs}

\section{Use of vsiRNAs to Induce Antiviral Resistance}

Current knowledge suggest RNA silencing make a great contribution to the resistance against pathogens on their respective crops (Nicaise, 2014). Whereas, naturally occurred vsiRNAs or miRNAs induced virus resistance is not enough for protecting the host plants from viral infection. By using hairpin constructs, dsRNA can be expressed in plants relatively easily, and RNA silencing is activated to silence the expression of genes of invading pathogens (Mansoor et al., 2006; Prins et al., 2008; Collinge et al., 2010). For viruses, this strategy is increasingly being used. Some cases directly characterize the application of vsiRNA in inducing antiviral resistance such as AsatsiR-12 (Zhu et al., 2011). However, many evidences indicating the application of vsiRNAs to induce antiviral resistance are indirect. In transgenic tobacco expressing hairpin RNA derived from TMV movement protein (MP) or CMV replication protein, two $\mathrm{T} 4$ transgenic lines with single copy were completely resistant to the corresponding virus (Hu et al., 2011). In rice, strong resistance is induced in transgenic rice plants expressing hairpin RNA of the viral genes, such as $R D V$ viroplasm matrix protein Pns12 (Shimizu et al., 2009), RSV CP (Park et al., 2012), Rice gall dwarf virus Pns9 (Shimizu et al., 2012), Rice grassy stunt virus CP or MP (Shimizu et al., 2013). In transgenic maize, expressing the hairpin structure transcribed from the CP gene of Sugarcane mosaic virus (SCMV) led to inhibition of SCMV infection, although to varying degrees (Gan et al., 2014). Thus, in a variety of crops, based on the knowledge of vsiRNAs-mediated antiviral RNA silencing, expressing hairpin constructs strategy has been a potential approach with high efficiency to combat the virus. 


\section{Use of vsiRNAs to Assemble Virus and Viroid Genomes}

Additionally, the complete genome of a certain virus can be reconstructed based on vsiRNAs derived from the virus by combining small RNA deep sequencing with de novo assembly of viral siRNAs using bioinformatics tools. For instance, RuizRuiz et al. (2011) used vsiRNAs sequencing to reconstruct the full genome of the T318A Spanish Citrus tristeza virus (CTV) isolate that infects sweet (Citrus sinensis Osbeck) and sour orange (C. aurantium L.) and Mexican lime (C. aurantifolia Christ.) seedlings. Seguin et al. (2014) reconstructed DNA viruses from Caulimoviridae and Geminiviridae families by utilizing this approach, subsequently, they also reconstructed an emerging DNA virus and two viroids associated with economically important red blotch disease of grapevine to verify that vsiRNAbased deep sequencing allows for de novo reconstruction of any DNA or RNA virus genome and its microvariants (Seguin et al., 2014). A new virus, Citrus vein enation virus (CVEV), was identified as the causal agent of citrus vein enation disease by deep sequencing sRNAs from infected and healthy Etrog citron plants (Vives et al., 2013). Another research group reported the presence of a Tobamovirus on Cicer arietinum in Europe for the first time and a viroid referring to Hop stunt viroid (NC_001351.1) was reported in chickpea based on short RNAs sequencing (Pirovano et al., 2014).

\section{Use of vsiRNAs to Study Viral Population Genetics}

Virus-derived small interfering RNAs-based deep sequencing was also used to survey the in planta virus population for the first time. Viral RNAs and vsiRNAs both congruently portrayed the mutational landscape of the virus within the plant host (Kutnjak et al., 2015). Next generation sequencing (NGS) technology has previously been shown to be a powerful tool for studying viral ecology (Stobbe and Roossinck, 2014) and viral populations (Beerenwinkel and Zagordi, 2011; Palmer et al., 2014; Chateigner et al., 2015; Skums et al., 2015). Nowadays, many population genetics experts prefer to study plant virus ecology or populations by sequencing the vsiRNAs. For instance, SG29 (aggressive) and Bau282 (mild), two representative isolates of a CTV population in Sicily, were sequenced from vsiRNAs of budlings of sweet orange grafted on sour orange trees. The phylogenetic relationships with Mediterranean and exotic isolates revealed that SG29 clustered within the "VT-Asian" subtype, whereas Bau282 belonged to cluster T30 (Licciardello et al., 2015). Notably, although vsiRNAsbased NGS technology is a more effective way to study virus ecology and populations, there is relatively high error rate. Thus, several computational pipelines such as ViVan (Isakov et al., 2015), ViVaMBC (Verbist et al., 2015), and LayerCake (Correll

\section{REFERENCES}

Addo-Quaye, C., Eshoo, T. W., Bartel, D. P., and Axtell, M. J. (2008). Endogenous siRNA and miRNA targets identified by sequencing of the Arabidopsis degradome. Curr. Biol. 18, 758-762. doi: 10.1016/j.cub.2008. 04.042 et al., 2015), tools with different applications for analyzing viral deep sequencing data, have been developed.

In summary, much of what we know already and what we will uncover in the future regarding plant viruses is possible by the study of vsiRNAs. Previous studies have proven that it is not only a feasible tool to control virus in crop plants by artificially expressing vsiRNAs, but also a high-throughput and costeffective approach for reconstructing viral genomes, discovering novel virus, and studying viral ecology and populations by vsiRNAs deep sequencing experiments.

\section{FUTURE CHALLENGES}

With the advance of NGS technologies, it is predicted that more studies using RNA profiling of plants infected with various pathogens will help identify more vsiRNAs. However, understanding the mechanism of action of vsiRNA-mediated antiviral silencing is a big challenge for researchers. Additionally, the interactions between host plants, viruses, and the abundant various vsiRNAs are extremely complex. The question of how to determine and classify the roles of a large number of vsiRNAs in the co-evolutionary battle between hosts and viruses also remains largely unanswered. Furthermore, it is unknown whether it is a general phenomenon that the vsiRNAs are able to induce disease by targeting host endogenous genes. Until now it is unknown whether vsiRNA-mediated endogenous gene silencing is a common mechanism in virusinfected plants. Albeit great advances have been made in our knowledge of sRNA-mediated plant immunity against viruses, studies on effective antiviral drugs against plant viruses and/or approaches on improving host resistance to virus disease are still deficient. Lastly, evidence suggests a potential method for controlling viral diseases is the expression of artificial sRNAs targeting the viral genome. However, any potential risks or safety issues of using this tool in crops must be evaluated.

\section{ACKNOWLEDGMENTS}

We thank Dr. Yifan Lii, Dr. Liang Wu, and Dr. Zhenguo Du for their critical reading of the manuscript. This work was supported by grants from the National Basic Research Program 973 (2014CB138403 and 2013CBA01402), Natural Science Foundation of China (31272018, 31201491 and 31171821), Natural Science Foundation of Fujian Province of China and Outstanding Young Scientific Research Plan in Higher Education of Fujian Province (2013J01089 and JA3091). We apologize for not citing some publications owing to space limitations.

Adkar-Purushothama, C. R., Brosseau, C., Giguere, T., Sano, T., Moffett, P., and Perreault, J. P. (2015). Small RNA derived from the virulence modulating region of the potato spindle tuber viroid silences callose synthase genes of tomato plants. Plant Cell 27, 2178-2194. doi: 10.1105/tpc.15.00523

Ahlquist, P. (2002). RNA-dependent RNA polymerases, viruses, and RNA silencing. Science 296, 1270-1273. doi: 10.1126/science.1069132 
Akbergenov, R., Si-Ammour, A., Blevins, T., Amin, I., Kutter, C., Vanderschuren, H., et al. (2006). Molecular characterization of geminivirusderived small RNAs in different plant species. Nucleic Acids Res. 34, 462-471. doi: 10.1093/nar/gkj447

Andika, I. B., Maruyama, K., Sun, L., Kondo, H., Tamada, T., and Suzuki, N. (2015). Different Dicer-like protein components required for intracellular and systemic antiviral silencing in Arabidopsis thaliana. Plant Signal. Behav. 10:e1039214. doi: 10.1080/15592324.2015.1039214

Aregger, M., Borah, B. K., Seguin, J., Rajeswaran, R., Gubaeva, E. G., Zvereva, A. S., et al. (2012). Primary and secondary siRNAs in geminivirus-induced gene silencing. PLoS Pathog 8:e1002941. doi: 10.1371/journal.ppat.1002941

Axtell, M. J. (2013). Classification and comparison of small RNAs from plants. Annu. Rev. Plant Biol. 64, 137-159. doi: 10.1146/annurev-arplant-050312120043

Beerenwinkel, N., and Zagordi, O. (2011). Ultra-deep sequencing for the analysis of viral populations. Curr. Opin. Virol. 1, 413-418. doi: 10.1016/j.coviro.2011.07.008

Ben Amor, B., Wirth, S., Merchan, F., Laporte, P., d'Aubenton-Carafa, Y., Hirsch, J., et al. (2009). Novel long non-protein coding RNAs involved in Arabidopsis differentiation and stress responses. Genome Res. 19, 57-69. doi: 10.1101/gr.080275.108

Blevins, T., Rajeswaran, R., Shivaprasad, P. V., Beknazariants, D., Si-Ammour, A., Park, H. S., et al. (2006). Four plant Dicers mediate viral small RNA biogenesis and DNA virus induced silencing. Nucleic Acids Res. 34, 6233-6246. doi: $10.1093 / \mathrm{nar} / \mathrm{gkl} 886$

Bouche, N., Lauressergues, D., Gasciolli, V., and Vaucheret, H. (2006). An antagonistic function for Arabidopsis DCL2 in development and a new function for DCL4 in generating viral siRNAs. EMBO J. 25, 3347-3356. doi: 10.1038/sj.emboj.7601217

Brosseau, C., and Moffett, P. (2015). Functional and genetic analysis identify a role for Arabidopsis ARGONAUTE5 in antiviral RNA silencing. Plant Cell 27, 1742-1754. doi: 10.1105/tpc.15.00264

Brough, C. L., Gardiner, W. E., Inamdar, N. M., Zhang, X. Y., Ehrlich, M., and Bisaro, D. M. (1992). DNA methylation inhibits propagation of tomato golden mosaic virus DNA in transfected protoplasts. Plant Mol. Biol. 18, 703-712. doi: 10.1007/BF00020012

Cao, M., Du, P., Wang, X., Yu, Y. Q., Qiu, Y. H., Li, W., et al. (2014). Virus infection triggers widespread silencing of host genes by a distinct class of endogenous siRNAs in Arabidopsis. Proc. Natl. Acad. Sci. U.S.A. 111, 14613-14618. doi: $10.1073 /$ pnas. 1407131111

Carbonell, A., and Carrington, J. C. (2015). Antiviral roles of plant ARGONAUTES. Curr. Opin. Plant Biol. 27, 111-117. doi: 10.1016/j.pbi.2015.06.013

Carbonell, A., Fahlgren, N., Garcia-Ruiz, H., Gilbert, K. B., Montgomery, T. A., Nguyen, T., et al. (2012). Functional analysis of three Arabidopsis ARGONAUTES using slicer-defective mutants. Plant Cell 24, 3613-3629. doi: 10.1105/tpc.112.099945

Chan, S. W., Zilberman, D., Xie, Z., Johansen, L. K., Carrington, J. C., and Jacobsen, S. E. (2004). RNA silencing genes control de novo DNA methylation. Science 303:1336. doi: 10.1126/science.1095989

Chateigner, A., Bezier, A., Labrousse, C., Jiolle, D., Barbe, V., and Herniou, E. A. (2015). Ultra deep sequencing of a baculovirus population reveals widespread genomic variations. Viruses 7, 3625-3646. doi: 10.3390/v7072788

Chellappan, P., Vanitharani, R., Pita, J., and Fauquet, C. M. (2004). Short interfering RNA accumulation correlates with host recovery in DNA virus-infected hosts, and gene silencing targets specific viral sequences. J. Virol. 78, 7465-7477. doi: 10.1128/JVI.78.14.7465-7477.2004

Collinge, D. B., Jorgensen, H. J., Lund, O. S., and Lyngkjaer, M. F. (2010). Engineering pathogen resistance in crop plants: current trends and future prospects. Annu. Rev. Phytopathol. 48, 269-291. doi: 10.1146/annurev-phyto073009-114430

Correll, M., Bailey, A. L., Sarikaya, A., O’Connor, D. H., and Gleicher, M. (2015). LayerCake: a tool for the visual comparison of viral deep sequencing data. Bioinformatics 31, 3522-3528. doi: 10.1093/bioinformatics/btv407

Csorba, T., Kontra, L., and Burgyan, J. (2015). Viral silencing suppressors: tools forged to fine-tune host-pathogen coexistence. Virology 479-480, 85-103. doi: 10.1016/j.virol.2015.02.028

Cuellar, W. J., Kreuze, J. F., Rajamaki, M. L., Cruzado, K. R., Untiveros, M., and Valkonen, J. P. (2009). Elimination of antiviral defense by viral RNase
III. Proc. Natl. Acad. Sci. U.S.A. 106, 10354-10358. doi: 10.1073/pnas.08060 42106

Dalmay, T., Hamilton, A., Rudd, S., Angell, S., and Baulcombe, D. C. (2000). An RNA-dependent RNA polymerase gene in Arabidopsis is required for posttranscriptional gene silencing mediated by a transgene but not by a virus. Cell 101, 543-553. doi: 10.1016/S0092-8674(00)80864-8

Deleris, A., Gallego-Bartolome, J., Bao, J., Kasschau, K. D., Carrington, J. C., and Voinnet, O. (2006). Hierarchical action and inhibition of plant Dicer-like proteins in antiviral defense. Science 313, 68-71. doi: 10.1126/science.1128214

Diaz-Pendon, J. A., Li, F., Li, W. X., and Ding, S. W. (2007). Suppression of antiviral silencing by cucumber mosaic virus $2 \mathrm{~b}$ protein in Arabidopsis is associated with drastically reduced accumulation of three classes of viral small interfering RNAs. Plant Cell 19, 2053-2063. doi: 10.1105/tpc.106.047449

Donaire, L., Barajas, D., Martinez-Garcia, B., Martinez-Priego, L., Pagan, I., and Llave, C. (2008). Structural and genetic requirements for the biogenesis of tobacco rattle virus-derived small interfering RNAs. J. Virol. 82, 5167-5177. doi: 10.1128/JVI.00272-08

Donaire, L., Wang, Y., Gonzalez-Ibeas, D., Mayer, K. F., Aranda, M. A., and Llave, C. (2009). Deep-sequencing of plant viral small RNAs reveals effective and widespread targeting of viral genomes. Virology 392, 203-214. doi: 10.1016/j.virol.2009.07.005

Dorssers, L., Zabel, P., van der Meer, J., and van Kammen, A. (1982). Purification of a host-encoded RNA-dependent RNA polymerase from cowpea mosaic virus-infected cowpea leaves. Virology 116, 236-249. doi: 10.1016/00426822(82)90416-0

Du, P., Wu, J., Zhang, J., Zhao, S., Zheng, H., Gao, G., et al. (2011a). Viral infection induces expression of novel phased microRNAs from conserved cellular microRNA precursors. PLoS Pathog 7:e1002176. doi: 10.1371/journal.ppat.1002176

Du, Z., Xiao, D., Wu, J., Jia, D., Yuan, Z., Liu, Y., et al. (2011b). p2 of rice stripe virus (RSV) interacts with OsSGS3 and is a silencing suppressor. Mol. Plant Pathol. 12, 808-814. doi: 10.1111/j.1364-3703.2011.00716.x

Dzianott, A., Sztuba-Solinska, J., and Bujarski, J. J. (2012). Mutations in the antiviral RNAi defense pathway modify Brome mosaic virus RNA recombinant profiles. Mol. Plant-Microbe Interact. 25, 97-106. doi: 10.1094/MPMI-05-110137

Earley, K. W., and Poethig, R. S. (2011). Binding of the cyclophilin 40 ortholog SQUINT to Hsp90 protein is required for SQUINT function in Arabidopsis. J. Biol. Chem. 286, 38184-38189. doi: 10.1074/jbc.M111.290130

El-Shami, M., Pontier, D., Lahmy, S., Braun, L., Picart, C., Vega, D., et al. (2007). Reiterated WG/GW motifs form functionally and evolutionarily conserved ARGONAUTE-binding platforms in RNAi-related components. Genes Dev. 21, 2539-2544. doi: 10.1101/gad.451207

Ermak, G., Paszkowski, U., Wohlmuth, M., Mittelsten Scheid, O., and Paszkowski, J. (1993). Cytosine methylation inhibits replication of African cassava mosaic virus by two distinct mechanisms. Nucleic Acids Res. 21, 3445 3450. doi: 10.1093/nar/21.15.3445

Fukunaga, R., and Doudna, J. A. (2009). dsRNA with 5' overhangs contributes to endogenous and antiviral RNA silencing pathways in plants. EMBO J. 28, 545-555. doi: 10.1038/emboj.2009.2

Fusaro, A. F., Matthew, L., Smith, N. A., Curtin, S. J., Dedic-Hagan, J., Ellacott, G. A., et al. (2006). RNA interference-inducing hairpin RNAs in plants act through the viral defence pathway. EMBO Rep. 7, 1168-1175. doi: 10.1038/sj.embor.7400837

Gan, D., Ding, F., Zhuang, D., Jiang, H., Jiang, T., Zhu, S., et al. (2014). Application of RNA interference methodology to investigate and develop SCMV resistance in maize. J. Genet. 93, 305-311. doi: 10.1007/s12041-014-0364-1

Garcia-Ruiz, H., Carbonell, A., Hoyer, J. S., Fahlgren, N., Gilbert, K. B., Takeda, A., et al. (2015). Roles and programming of Arabidopsis ARGONAUTE proteins during turnip mosaic virus infection. PLoS Pathog 11:e1004755. doi: 10.1371/journal.ppat.1004755

Garcia-Ruiz, H., Takeda, A., Chapman, E. J., Sullivan, C. M., Fahlgren, N., Brempelis, K. J., et al. (2010). Arabidopsis RNA-dependent RNA polymerases and dicer-like proteins in antiviral defense and small interfering RNA biogenesis during Turnip Mosaic Virus infection. Plant Cell 22, 481-496. doi: 10.1105/tpc.109.073056

Gasciolli, V., Mallory, A. C., Bartel, D. P., and Vaucheret, H. (2005). Partially redundant functions of Arabidopsis DICER-like enzymes and a role for 
DCL4 in producing trans-acting siRNAs. Curr. Biol. 15, 1494-1500. doi: 10.1016/j.cub.2005.07.024

Ghoshal, B., and Sanfaçon, H. (2014). Temperature-dependent symptom recovery in Nicotiana benthamiana plants infected with tomato ringspot virus is associated with reduced translation of viral RNA2 and requires ARGONAUTE 1. Virology 456-457, 188-197. doi: 10.1016/j.virol.2014.03.026

Gillet, F. X., Cattoni, D. I., Petiot-Becard, S., Delalande, F., Poignavent, V., Brizard, J. P., et al. (2013). The RYMV-encoded viral suppressor of RNA silencing P1 is a zinc-binding protein with redox-dependent flexibility. J. Mol. Biol. 425, 2423-2435. doi: 10.1016/j.jmb.2013.03.028

Glick, E., Zrachya, A., Levy, Y., Mett, A., Gidoni, D., Belausov, E., et al. (2008). Interaction with host SGS3 is required for suppression of RNA silencing by tomato yellow leaf curl virus V2 protein. Proc. Natl. Acad. Sci. U.S.A. 105, 157-161. doi: 10.1073/pnas.0709036105

Goto, K., Kobori, T., Kosaka, Y., Natsuaki, T., and Masuta, C. (2007). Characterization of silencing suppressor $2 \mathrm{~b}$ of cucumber mosaic virus based on examination of its small RNA-binding abilities. Plant Cell Physiol. 48, 1050-1060. doi: 10.1093/pcp/pcm074

Guo, H., Song, X., Xie, C., Huo, Y., Zhang, F., Chen, X., et al. (2013). Rice yellow stunt rhabdovirus protein 6 suppresses systemic RNA silencing by blocking RDR6-mediated secondary siRNA synthesis. Mol. Plant-Microbe Interact. 26, 927-936. doi: 10.1094/MPMI-02-13-0040-R

Hamilton, A. J., and Baulcombe, D. C. (1999). A species of small antisense RNA in posttranscriptional gene silencing in plants. Science 286, 950-952. doi: 10.1126/science.286.5441.950

Harfouche, L., Haichar Fel, Z., and Achouak, W. (2015). Small regulatory RNAs and the fine-tuning of plant-bacteria interactions. New Phytol. 206, 98-106. doi: 10.1111/nph.13195

Harvey, J. J., Lewsey, M. G., Patel, K., Westwood, J., Heimstadt, S., Carr, J. P., et al. (2011). An antiviral defense role of AGO2 in plants. PLoS ONE 6:e14639. doi: 10.1371/journal.pone.0014639

Henderson, I. R., Zhang, X., Lu, C., Johnson, L., Meyers, B. C., Green, P. J., et al. (2006). Dissecting Arabidopsis thaliana DICER function in small RNA processing, gene silencing and DNA methylation patterning. Nat. Genet. 38, 721-725. doi: 10.1038/ng1804

Hong, W., Qian, D., Sun, R., Jiang, L., Wang, Y., Wei, C., et al. (2015). OsRDR6 plays role in host defense against double-stranded RNA virus, Rice Dwarf Phytoreovirus. Sci. Rep. 5:11324. doi: 10.1038/srep11324

$\mathrm{Hu}, \mathrm{Q}$., Niu, Y., Zhang, K., Liu, Y., and Zhou, X. (2011). Virus-derived transgenes expressing hairpin RNA give immunity to Tobacco mosaic virus and Cucumber mosaic virus. Virol. J. 8:41. doi: 10.1186/1743-422X-8-41

Iki, T., Yoshikawa, M., Meshi, T., and Ishikawa, M. (2012). Cyclophilin 40 facilitates HSP90-mediated RISC assembly in plants. EMBO J. 31, 267-278. doi: 10.1038/emboj.2011.395

Iki, T., Yoshikawa, M., Nishikiori, M., Jaudal, M. C., Matsumoto-Yokoyama, E., Mitsuhara, I., et al. (2010). In vitro assembly of plant RNA-induced silencing complexes facilitated by molecular chaperone HSP90. Mol. cell 39, 282-291. doi: 10.1016/j.molcel.2010.05.014

Isakov, O., Borderia, A. V., Golan, D., Hamenahem, A., Celniker, G., Yoffe, L., et al. (2015). Deep sequencing analysis of viral infection and evolution allows rapid and detailed characterization of viral mutant spectrum. Bioinformatics 31 , 2141-2150. doi: 10.1093/bioinformatics/btv101

Jiang, L., Qian, D., Zheng, H., Meng, L. Y., Chen, J., Le, W. J., et al. (2012). RNAdependent RNA polymerase 6 of rice (Oryza sativa) plays role in host defense against negative-strand RNA virus, Rice stripe virus. Virus Res. 163, 512-519. doi: 10.1016/j.virusres.2011.11.016

Karran, R. A., and Sanfacon, H. (2014). Tomato ringspot virus coat protein binds to ARGONAUTE 1 and suppresses the translation repression of a reporter gene. Mol. Plant-Microbe Interact. 27, 933-943. doi: 10.1094/MPMI-04-14-0099-R

Koukiekolo, R., Jakubek, Z. J., Cheng, J., Sagan, S. M., and Pezacki, J. P. (2009). Studies of a viral suppressor of RNA silencing p19-CFP fusion protein: a FRET-based probe for sensing double-stranded fluorophore tagged small RNAs. Biophys. Chem. 143, 166-169. doi: 10.1016/j.bpc.2009.05.001

Kreuze, J. F., Savenkov, E. I., Cuellar, W., Li, X., and Valkonen, J. P. (2005). Viral class 1 RNase III involved in suppression of RNA silencing. J. Virol. 79, 7227-7238. doi: 10.1128/JVI.79.11.7227-7238.2005

Kumakura, N., Takeda, A., Fujioka, Y., Motose, H., Takano, R., and Watanabe, Y. (2009). SGS3 and RDR6 interact and colocalize in cytoplasmic
SGS3/RDR6-bodies. FEBS Lett. 583, 1261-1266. doi: 10.1016/j.febslet.2009. 03.055

Kutnjak, D., Rupar, M., Gutierrez-Aguirre, I., Curk, T., Kreuze, J. F., and Ravnikar, M. (2015). Deep sequencing of virus-derived small interfering RNAs and RNA from viral particles shows highly similar mutational landscapes of a plant virus population. J. Virol. 89, 4760-4769. doi: 10.1128/JVI.03685-14

Lacombe, S., Bangratz, M., Vignols, F., and Brugidou, C. (2010). The rice yellow mottle virus $\mathrm{P} 1$ protein exhibits dual functions to suppress and activate gene silencing. Plant J. 61, 371-382. doi: 10.1111/j.1365-313X.2009.04062.x

Li, Y. F., Zheng, Y., Jagadeeswaran, G., and Sunkar, R. (2013). Characterization of small RNAs and their target genes in wheat seedlings using sequencing-based approaches. Plant Sci. 203-204, 17-24. doi: 10.1016/j.plantsci.2012.12.014

Licciardello, G., Scuderi, G., Ferraro, R., Giampetruzzi, A., Russo, M., Lombardo, A., et al. (2015). Deep sequencing and analysis of small RNAs in sweet orange grafted on sour orange infected with two Citrus tristeza virus isolates prevalent in Sicily. Arch. Virol. 160, 2583-2589. doi: 10.1007/s00705015-2516-x

Liu, B., Chen, Z., Song, X., Liu, C., Cui, X., Zhao, X., et al. (2007). Oryza sativa dicer-like4 reveals a key role for small interfering RNA silencing in plant development. Plant Cell 19, 2705-2718. doi: 10.1105/tpc.107.052209

Ma, X., Nicole, M. C., Meteignier, L. V., Hong, N., Wang, G., and Moffett, P. (2015). Different roles for RNA silencing and RNA processing components in virus recovery and virus-induced gene silencing in plants. J. Exp. Bot. 66, 919-932. doi: $10.1093 / \mathrm{jxb} / \mathrm{eru} 447$

Mallory, A. C., and Vaucheret, H. (2009). ARGONAUTE 1 homeostasis invokes the coordinate action of the microRNA and siRNA pathways. EMBO Rep. 10, 521-526. doi: 10.1038/embor.2009.32

Mallory, A., and Vaucheret, H. (2010). Form, function, and regulation of ARGONAUTE proteins. Plant Cell 22, 3879-3889. doi: 10.1105/tpc.110.080671

Mansoor, S., Amin, I., Hussain, M., Zafar, Y., and Briddon, R. W. (2006). Engineering novel traits in plants through RNA interference. Trends Plant Sci. 11, 559-565. doi: 10.1016/j.tplants.2006.09.010

Martinez de Alba, A. E., Elvira-Matelot, E., and Vaucheret, H. (2013). Gene silencing in plants: a diversity of pathways. Biochim. Biophys. Acta 1829, 1300-1308. doi: 10.1016/j.bbagrm.2013.10.005

Martinez de Alba, A. E., Moreno, A. B., Gabriel, M., Mallory, A. C., Christ, A., Bounon, R., et al. (2015). In plants, decapping prevents RDR6-dependent production of small interfering RNAs from endogenous mRNAs. Nucleic Acids Res. 43, 2902-2913. doi: 10.1093/nar/gkv119

Mayor, A., Martinon, F., De Smedt, T., Petrilli, V., and Tschopp, J. (2007). A crucial function of SGT1 and HSP90 in inflammasome activity links mammalian and plant innate immune responses. Nat. Immunol. 8, 497-503. doi: 10.1038/ ni1459

Merai, Z., Kerenyi, Z., Molnar, A., Barta, E., Valoczi, A., Bisztray, G., et al. (2005). Aureusvirus P14 is an efficient RNA silencing suppressor that binds double-stranded RNAs without size specificity. J. Virol. 79, 7217-7226. doi: 10.1128/JVI.79.11.7217-7226.2005

Miozzi, L., Gambino, G., Burgyan, J., and Pantaleo, V. (2013). Genome-wide identification of viral and host transcripts targeted by viral siRNAs in Vitis vinifera. Mol. Plant Pathol. 14, 30-43. doi: 10.1111/j.1364-3703.2012.00828.x

Moissiard, G., and Voinnet, O. (2006). RNA silencing of host transcripts by cauliflower mosaic virus requires coordinated action of the four Arabidopsis Dicer-like proteins. Proc. Natl. Acad. Sci. U.S.A. 103, 19593-19598. doi: 10.1073/pnas.0604627103

Molnar, A., Csorba, T., Lakatos, L., Varallyay, E., Lacomme, C., and Burgyan, J. (2005). Plant virus-derived small interfering RNAs originate predominantly from highly structured single-stranded viral RNAs. J. Virol. 79, 7812-7818. doi: 10.1128/JVI.79.12.7812-7818.2005

Morel, J. B., Godon, C., Mourrain, P., Beclin, C., Boutet, S., Feuerbach, F., et al. (2002). Fertile hypomorphic ARGONAUTE (ago1) mutants impaired in posttranscriptional gene silencing and virus resistance. Plant Cell 14, 629-639. doi: 10.1105/tpc.010358

Mourrain, P., Beclin, C., Elmayan, T., Feuerbach, F., Godon, C., Morel, J. B., et al. (2000). Arabidopsis SGS2 and SGS3 genes are required for posttranscriptional gene silencing and natural virus resistance. Cell 101, 533542. doi: 10.1016/S0092-8674(00)80863-6

Navarro, B., Gisel, A., Rodio, M. E., Delgado, S., Flores, R., and Di Serio, F. (2012). Small RNAs containing the pathogenic determinant of a chloroplast-replicating 
viroid guide the degradation of a host mRNA as predicted by RNA silencing. Plant J. 70, 991-1003. doi: 10.1111/j.1365-313X.2012.04940.x

Nicaise, V. (2014). Crop immunity against viruses: outcomes and future challenges. Front. Plant Sci. 5:660. doi: 10.3389/fpls.2014.00660

Nonomura, K., Morohoshi, A., Nakano, M., Eiguchi, M., Miyao, A., Hirochika, H., et al. (2007). A germ cell specific gene of the ARGONAUTE family is essential for the progression of premeiotic mitosis and meiosis during sporogenesis in rice. Plant Cell 19, 2583-2594. doi: 10.1105/tpc.107.053199

Odokonyero, D., Mendoza, M. R., Alvarado, V. Y., Zhang, J., Wang, X., and Scholthof, H. B. (2015). Transgenic down-regulation of ARGONAUTE2 expression in Nicotiana benthamiana interferes with several layers of antiviral defenses. Virology 486, 209-218. doi: 10.1016/j.virol.2015.09.008

Palmer, B. A., Dimitrova, Z., Skums, P., Crosbie, O., Kenny-Walsh, E., and Fanning, L. J. (2014). Analysis of the evolution and structure of a complex intrahost viral population in chronic hepatitis $\mathrm{C}$ virus mapped by ultradeep pyrosequencing. J. Virol. 88, 13709-13721. doi: 10.1128/JVI.01732-14

Park, H. M., Choi, M. S., Kwak, D. Y., Lee, B. C., Lee, J. H., Kim, M. K., et al. (2012). Suppression of NS3 and MP is important for the stable inheritance of RNAi-mediated rice stripe virus (RSV) resistance obtained by targeting the fully complementary RSV-CP gene. Mol. Cells 33, 43-51. doi: 10.1007/s10059-0122185-5

Pirovano, W., Miozzi, L., Boetzer, M., and Pantaleo, V. (2014). Bioinformatics approaches for viral metagenomics in plants using short RNAs: model case of study and application to a Cicer arietinum population. Front. Microbiol. 5:790. doi: $10.3389 /$ fmicb. 2014.00790

Poulsen, C., Vaucheret, H., and Brodersen, P. (2013). Lessons on RNA silencing mechanisms in plants from eukaryotic argonaute structures. Plant Cell 25, 22-37. doi: 10.1105/tpc.112.105643

Prins, M., Laimer, M., Noris, E., Schubert, J., Wassenegger, M., and Tepfer, M. (2008). Strategies for antiviral resistance in transgenic plants. Mol. Plant Pathol. 9, 73-83. doi: 10.1111/j.1364-3703.2007.00447.x

Qi, X., Bao, F. S., and Xie, Z. (2009). Small RNA deep sequencing reveals role for Arabidopsis thaliana RNA-dependent RNA polymerases in viral siRNA biogenesis. PLoS ONE 4:e4971. doi: 10.1371/journal.pone. 0004971

Qu, F., Ren, T., and Morris, T. J. (2003). The coat protein of turnip crinkle virus suppresses posttranscriptional gene silencing at an early initiation step. J. Virol. 77, 511-522. doi: 10.1128/JVI.77.1.511-522.2003

Qu, F., Ye, X., and Morris, T. J. (2008). Arabidopsis DRB4, AGO1, AGO7, and RDR6 participate in a DCL4-initiated antiviral RNA silencing pathway negatively regulated by DCL1. Proc. Natl. Acad. Sci. U.S.A. 105, 14732-14737. doi: 10.1073/pnas.0805760105

Raja, P., Jackel, J. N., Li, S., Heard, I. M., and Bisaro, D. M. (2014). Arabidopsis double-stranded RNA binding protein DRB3 participates in methylation-mediated defense against geminiviruses. J. Virol. 88, 2611-2622. doi: 10.1128/JVI.02305-13

Raja, P., Sanville, B. C., Buchmann, R. C., and Bisaro, D. M. (2008). Viral genome methylation as an epigenetic defense against geminiviruses. J. Virol. 82, 89979007. doi: 10.1128/JVI.00719-08

Rajagopalan, R., Vaucheret, H., Trejo, J., and Bartel, D. P. (2006). A diverse and evolutionarily fluid set of microRNAs in Arabidopsis thaliana. Genes Dev. 20, 3407-3425. doi: 10.1101/gad.1476406

Ren, B., Guo, Y., Gao, F., Zhou, P., Wu, F., Meng, Z., et al. (2010). Multiple functions of Rice dwarf phytoreovirus Pns10 in suppressing systemic RNA silencing. J. Virol. 84, 12914-12923. doi: 10.1128/JVI.00864-10

Romaine, C. P., and Zaitlin, M. (1978). RNA-dependent RNA polymerases in uninfected and tobacco mosaic virus-infected tabacco leaves: viral induced stimulation of a host polymerase activity. Virology 86, 241-253. doi: 10.1016/0042-6822(78)90024-7

Ruiz-Ruiz, S., Navarro, B., Gisel, A., Pena, L., Navarro, L., Moreno, P., et al. (2011). Citrus tristeza virus infection induces the accumulation of viral small RNAs (21-24-nt) mapping preferentially at the 3'-terminal region of the genomic RNA and affects the host small RNA profile. Plant Mol. Biol. 75, 607-619. doi: 10.1007/s11103-011-9754-4

Scholthof, H. B., Alvarado, V. Y., Vega-Arreguin, J. C., Ciomperlik, J., Odokonyero, D., Brosseau, C., et al. (2011). Identification of an ARGONAUTE for antiviral RNA silencing in Nicotiana benthamiana. Plant Physiol. 156, 1548-1555. doi: 10.1104/pp.111.178764
Schuck, J., Gursinsky, T., Pantaleo, V., Burgyan, J., and Behrens, S. E. (2013). AGO/RISC-mediated antiviral RNA silencing in a plant in vitro system. Nucleic Acids Res. 41, 5090-5103. doi: 10.1093/nar/gkt193

Schwach, F., Vaistij, F. E., Jones, L., and Baulcombe, D. C. (2005). An RNAdependent RNA polymerase prevents meristem invasion by potato virus $\mathrm{X}$ and is required for the activity but not the production of a systemic silencing signal. Plant Physiol. 138, 1842-1852. doi: 10.1104/pp.105.063537

Seguin, J., Rajeswaran, R., Malpica-Lopez, N., Martin, R. R., Kasschau, K., Dolja, V. V., et al. (2014). De novo reconstruction of consensus master genomes of plant RNA and DNA viruses from siRNAs. PLoS ONE 9:e88513. doi: 10.1371/journal.pone.0088513

Shimizu, T., Nakazono-Nagaoka, E., Akita, F., Wei, T., Sasaya, T., Omura, T., et al. (2012). Hairpin RNA derived from the gene for Pns9, a viroplasm matrix protein of Rice gall dwarf virus, confers strong resistance to virus infection in transgenic rice plants. J. Biotechnol. 157, 421-427. doi: 10.1016/j.jbiotec.2011.12.015

Shimizu, T., Ogamino, T., Hiraguri, A., Nakazono-Nagaoka, E., Uehara-Ichiki, T., Nakajima, M., et al. (2013). Strong resistance against Rice grassy stunt virus is induced in transgenic rice plants expressing double-stranded RNA of the viral genes for nucleocapsid or movement proteins as targets for RNA interference. Phytopathology 103, 513-519. doi: 10.1094/PHYTO-07-120165-R

Shimizu, T., Yoshii, M., Wei, T., Hirochika, H., and Omura, T. (2009). Silencing by RNAi of the gene for Pns12, a viroplasm matrix protein of Rice dwarf virus, results in strong resistance of transgenic rice plants to the virus. Plant Biotechnol. J. 7, 24-32. doi: 10.1111/j.1467-7652.2008.00366.x

Shimura, H., Pantaleo, V., Ishihara, T., Myojo, N., Inaba, J., Sueda, K., et al. (2011). A viral satellite RNA induces yellow symptoms on tobacco by targeting a gene involved in chlorophyll biosynthesis using the RNA silencing machinery. PLoS Pathog 7:e1002021. doi: 10.1371/journal.ppat.1002021

Simon-Mateo, C., and Garcia, J. A. (2006). MicroRNA-guided processing impairs Plum pox virus replication, but the virus readily evolves to escape this silencing mechanism. J. Virol. 80, 2429-2436. doi: 10.1128/JVI.80.5.24292436.2006

Skums, P., Artyomenko, A., Glebova, O., Ramachandran, S., Mandoiu, I., Campo, D. S., et al. (2015). Computational framework for next-generation sequencing of heterogeneous viral populations using combinatorial pooling. Bioinformatics 31, 682-690. doi: 10.1093/bioinformatics/btu726

Stobbe, A. H., and Roossinck, M. J. (2014). Plant virus metagenomics: what we know and why we need to know more. Front. Plant Sci. 5:150. doi: $10.3389 /$ fpls. 2014.00150

Szittya, G., and Burgyan, J. (2013). RNA interference-mediated intrinsic antiviral immunity in plants. Curr. Top. Microbiol. Immunol. 371, 153-181. doi: 10.1007/978-3-642-37765-5_6

Szittya, G., Moxon, S., Pantaleo, V., Toth, G., Rusholme Pilcher, R. L., Moulton, V., et al. (2010). Structural and functional analysis of viral siRNAs. PLoS Pathog 6:e1000838. doi: 10.1371/journal.ppat.1000838

Urayama, S., Moriyama, H., Aoki, N., Nakazawa, Y., Okada, R., Kiyota, E., et al. (2010). Knock-down of OsDCL2 in rice negatively affects maintenance of the endogenous dsRNA virus, Oryza sativa endornavirus. Plant Cell Physiol. 51, 58-67. doi: 10.1093/pcp/pcp167

Vanitharani, R., Chellappan, P., and Fauquet, C. M. (2005). Geminiviruses and RNA silencing. Trends Plant Sci. 10, 144-151. doi: 10.1016/j.tplants.2005.01.005

Vaucheret, H. (2008). Plant ARGONAUTES. Trends Plant Sci. 13, 350-358. doi: 10.1016/j.tplants.2008.04.007

Verbist, B., Clement, L., Reumers, J., Thys, K., Vapirev, A., Talloen, W., et al. (2015). ViVaMBC: estimating viral sequence variation in complex populations from illumina deep-sequencing data using model-based clustering. BMC Bioinformatics 16:59. doi: 10.1186/s12859-015-0458-7

Visser, M., Maree, H. J., Rees, D. J., and Burger, J. T. (2014). High-throughput sequencing reveals small RNAs involved in ASGV infection. BMC Genomics 15:568. doi: 10.1186/1471-2164-15-568

Vives, M. C., Velazquez, K., Pina, J. A., Moreno, P., Guerri, J., and Navarro, L. (2013). Identification of a new enamovirus associated with citrus vein enation disease by deep sequencing of small RNAs. Phytopathology 103, 1077-1086. doi: 10.1094/PHYTO-03-13-0068-R

Voinnet, O. (2008). Use, tolerance and avoidance of amplified RNA silencing by plants. Trends Plant Sci. 13, 317-328. doi: 10.1016/j.tplants.2008.05.004 
Wang, H., Buckley, K. J., Yang, X., Buchmann, R. C., and Bisaro, D. M. (2005). Adenosine kinase inhibition and suppression of RNA silencing by geminivirus AL2 and L2 proteins. J. Virol. 79, 7410-7418. doi: 10.1128/JVI.79.12.74107418.2005

Wang, H., Hao, L., Shung, C. Y., Sunter, G., and Bisaro, D. M. (2003). Adenosine kinase is inactivated by geminivirus AL2 and L2 proteins. Plant Cell 15, 3020-3032. doi: 10.1105/tpc.015180

Wang, X. B., Jovel, J., Udomporn, P., Wang, Y., Wu, Q., Li, W. X., et al. (2011). The 21-nucleotide, but not 22-nucleotide, viral secondary small interfering RNAs direct potent antiviral defense by two cooperative argonautes in Arabidopsis thaliana. Plant Cell 23, 1625-1638. doi: 10.1105/tpc.110.082305

Wang, X. B., Wu, Q., Ito, T., Cillo, F., Li, W. X., Chen, X., et al. (2010). RNAi-mediated viral immunity requires amplification of virus-derived siRNAs in Arabidopsis thaliana. Proc. Natl. Acad. Sci. U.S.A. 107, 484-489. doi: 10.1073/pnas.0904086107

Weiberg, A., and Jin, H. (2015). Small RNAs-the secret agents in the plant-pathogen interactions. Curr. Opin. Plant Biol. 26, 87-94. doi: 10.1016/j.pbi.2015.05.033

Weinheimer, I., Boonrod, K., Moser, M., Zwiebel, M., Fullgrabe, M., Krczal, G., et al. (2010). Analysis of an autoproteolytic activity of rice yellow mottle virus silencing suppressor P1. Biol. Chem. 391, 271-281. doi: 10.1515/BC.2010.022

Wieczorek, P., and Obrepalska-Steplowska, A. (2015). Suppress to surviveimplication of plant viruses in PTGS. Plant Mol. Biol. Rep. 33, 335-346. doi: 10.1007/s11105-014-0755-8

Wu, J., Yang, Z., Wang, Y., Zheng, L., Ye, R., Ji, Y., et al. (2015). Viral-inducible argonaute 18 confers broad-spectrum virus resistance in rice by sequestering a host microRNA. Elife 17:4. doi: 10.7554/eLife.05733

Xie, M., Zhang, S., and Yu, B. (2015). microRNA biogenesis, degradation and activity in plants. Cell. Mol. Life Sci. 72, 87-99. doi: 10.1007/s00018-014-1728-7

Xie, Z., Fan, B., Chen, C., and Chen, Z. (2001). An important role of an inducible RNA-dependent RNA polymerase in plant antiviral defense. Proc. Natl. Acad. Sci. U.S.A. 98, 6516-6521. doi: 10.1073/pnas.111440998

Xie, Z., Johansen, L. K., Gustafson, A. M., Kasschau, K. D., Lellis, A. D., Zilberman, D., et al. (2004). Genetic and functional diversification of small RNA pathways in plants. PLoS Biol. 2:E104. doi: 10.1371/journal.pbio.0020104

Xiong, R., Wu, J., Zhou, Y., and Zhou, X. (2009). Characterization and subcellular localization of an RNA silencing suppressor encoded by Rice stripe tenuivirus. Virology 387, 29-40. doi: 10.1016/j.virol.2009.01.045
Xu, Y., Huang, L., Fu, S., Wu, J., and Zhou, X. (2012). Population diversity of rice stripe virus-derived siRNAs in three different hosts and RNAi-based antiviral immunity in Laodelphgax striatellus. PLoS ONE 7:e46238. doi: 10.1371/journal.pone.0046238

Yang, L. P., Fang, Y. Y., An, C. P., Dong, L., Zhang, Z. H., Chen, H., et al. (2013). C2-mediated decrease in DNA methylation, accumulation of siRNAs, and increase in expression for genes involved in defense pathways in plants infected with beet severe curly top virus. Plant J. 73, 910-917. doi: 10.1111/ tpj. 12081

Yang, L., Wu, G., and Poethig, R. S. (2012). Mutations in the GW-repeat protein SUO reveal a developmental function for microRNA-mediated translational repression in Arabidopsis. Proc. Natl. Acad. Sci. U.S.A. 109, 315-320. doi: 10.1073/pnas.1114673109

Zhang, B. (2015). MicroRNA: a new target for improving plant tolerance to abiotic stress. J. Exp. Bot. 66, 1749-1761. doi: 10.1093/jxb/erv013

Zhang, X., Zhang, X., Singh, J., Li, D., and Qu, F. (2012). Temperature-dependent survival of Turnip crinkle virus-infected arabidopsis plants relies on an RNA silencing-based defense that requires dcl2, AGO2, and HEN1. J. Virol. 86, 6847-6854. doi: 10.1128/JVI.00497-12

Zhu, H., Duan, C. G., Hou, W. N., Du, Q. S., Lv, D. Q., Fang, R. X., et al. (2011). Satellite RNA-derived small interfering RNA satsiR-12 targeting the 3' untranslated region of Cucumber mosaic virus triggers viral RNAs for degradation. J. Virol. 85, 13384-13397. doi: 10.1128/JVI.05806-11

Zong, J., Yao, X., Yin, J., Zhang, D., and Ma, H. (2009). Evolution of the RNAdependent RNA polymerase (RdRP) genes: duplications and possible losses before and after the divergence of major eukaryotic groups. Gene 447, 29-39. doi: 10.1016/j.gene.2009.07.004

Conflict of Interest Statement: The authors declare that the research was conducted in the absence of any commercial or financial relationships that could be construed as a potential conflict of interest.

Copyright (C) 2015 Zhang, Wu, Li and Wu. This is an open-access article distributed under the terms of the Creative Commons Attribution License (CC BY). The use, distribution or reproduction in other forums is permitted, provided the original author(s) or licensor are credited and that the original publication in this journal is cited, in accordance with accepted academic practice. No use, distribution or reproduction is permitted which does not comply with these terms. 